\title{
Metalinguistic Intuitions and Dominant Language Transfer in Heritage Spanish Syllabification
}

\author{
Michael Shelton \\ Occidental College \\ David Counselman \\ Ohio Wesleyan University \\ Nicolás Gutiérrez Palma
Universidad de Jaén
}

\begin{abstract}
While heritage speakers of Spanish have been shown to differ from monolingual speakers along many morphosyntactic lines, comparatively few studies in heritage linguistics have focused on phonology. To test whether the knowledge of English phonotactics would influence SpanishEnglish heritage speaker syllabification patterns in Spanish, 29 heritage and 29 monolingual speakers of Spanish completed a paper-and-pencil syllabification task in which they divided 80 Spanish words into syllables. Stimuli were controlled for comparisons between Spanish and English phonotactic constraints. Specific attention was placed on the syllabification of vocalic sequences as diphthongs or hiatus. Based on the distribution of diphthongs in English, and the findings of cognate effects in a similar study by Zárate-Sández (2011), heritage speakers were predicted to break diphthongs into hiatus more often in cognates than noncognates, more often when the English translation of a cognate presented hiatus, more in rising diphthongs than in falling diphthongs, and more often when a rising diphthong contained a palatal rather than velar glide. These effects were all present in heritage speaker results. No significant effects were found for monolingual controls. These findings offer new data to the understudied field of heritage phonology and to the ongoing discussion of dominant language transfer effects.
\end{abstract}

Keywords: Spanish, heritage speakers, phonology, metalinguistic intuitions, dominant language transfer, syllabification, cognates, diphthongs

\section{INTRODUCTION}

Until recently, few studies in heritage linguistics had focused on phonology. Many had assumed a native-like acquisition of the first language (L1) phonological grammar, due to the benefits of early exposure (e.g., Au, Oh, Knightly, Jun, \& Romo, 2008). There is, however, a growing body of work that has questioned this assumption (Benmamoun, Montrul, \& Polinsky, 2010; Montrul, 2012a; Rao \& Ronquest, 2015). These studies have begun to explore phonetic and phonological differences, both in perception and production, among heritage, monolingual, and late second language (L2) speakers.

Most work on heritage phonology in Spanish has focused on segmental differences between heritage populations and their monolingual Spanish-speaking counterparts. For example, in two articles exploring differences among consonants, Rao (2014, 2015) explored heritage speakers' use of the Spanish voiced spirants. In the first, he examined the production of $/ b /$ in intervocalic 
position, showing that, while the expected native-like pure approximant allophone surfaces most of the time, heritage speakers also produce less native-like targets, such as tense approximants and stops, particularly in stressed syllables, when reading aloud, and across word boundaries. In the second article, Rao (2015) expanded his previous work to include /d/ and /g/. He observed results similar to those for $/ \mathrm{b} /$ but found more native-like production of $/ \mathrm{d} /$ and $/ \mathrm{g} /$ among heritage speakers. Henriksen (2015) and Amengual (2016) also examined consonantal differences between heritage and monolingual speakers in their production of the Spanish trill/tap contrast. These studies report that both participant groups maintain the distinction between taps and trills by means of segment duration, but they also differ in the amount of lingual contacts or occlusions produced for each phoneme. These findings suggest that heritage speakers exploit the limits of phonetic variation in ways that differ from monolingual speakers, while still maintaining phonological contrasts.

Similarly, researchers have also begun to explore differences between heritage and monolingual production and perception of vowels. Ronquest (2013) tested to what extent stress influences vowel quality and quantity among bilingual speakers of Mexican or Puerto Rican Spanish and American English, given the tendency in English to reduce vowels in unstressed position. Utilizing a picture identification task, she found that heritage speakers produced unstressed vowels with both a more centralized articulation and a shorter duration than their tonic comparisons. Alvord and Rogers (2014) report similar findings for Miami Cubans. In addition to production studies, differences between heritage speakers and monolinguals have been identified in vowel perception tasks as well. For example, the results of Boomershine (2013) reveal a pattern in which heritage speakers pattern significantly differently from their native speaker counterparts in their ability to distinguish four English contrastive vowel pairs.

As highlighted in the previous studies, there has been a tendency in the literature to focus on differences in segmental features between heritage and monolingual populations. At the suprasegmental level, one finds fewer studies, although some recent work has uncovered differences in heritage prosodic structure. Colantoni, Cuza, and Mazzaro (2016), for example, explored intonational patterns among Mexican Spanish heritage speakers born in the U.S. and long-term immigrants from Mexico. The analysis of broad focus declaratives in a reading task revealed that heritage speakers divide utterances into more intonational phrases finishing with longer, steeper rises than those of long-term immigrants. Rao (2016) also presents data showing that heritage speakers display more limited variation in boundary tones in statements as well as nuclear configurations for questions that differ from previously published monolingual patterns. Focusing on verbal stress, Kim (2015) explored prosodic differences as well, between native speakers, L2 learners, and heritage speakers of Spanish in perception and production tasks. She found that heritage speakers evidence native-like perception of stress minimal pairs such as paso ['pa.so] 'I pass' versus pasó [pa.'so] 'he/she passed' but pattern more closely with L2 speakers in the production of vowel length in certain stress patterns. Also comparing durational differences, Harris and Gries (2011) explored the interaction of multiple language-rhythm measures with corpus frequency in the speech of monolingual speakers of Mexican Spanish and bilingual Mexican Americans in California. Their results suggest that bilingual Chicano Spanish exhibits a higher degree of variability in vowel length, more consistent with an English-like stress-timed 
rhythm than the less variable syllable-timed rhythm present in the speech of the monolingual Mexican participants.

While the studies reviewed above have addressed the nature of the syllable in heritage speech, such as syllable length differences as a function of stress placement, no study to-date has focused explicitly on heritage speaker syllabification or cross-language subsyllabic structural differences. The present study is a first step towards filling this gap. Its goal is two-fold. First, heritage phonotactics has received scare attention in the literature. The current study explores this understudied subfield of heritage phonology in an attempt to understand better how competing phonotactic constraints on syllable structure are mediated in the heritage speaker mind. Second, experimental work that examines the role of dominance in transfer effects between a heritage speaker's two languages has been conducted almost exclusively in the morphosyntactic domain. The results of this study have implications for and offer further examples from phonology of dominant language transfer among bilingual speakers of Spanish. Below we present the results of an experiment that tested how high fluency in English may influence Spanish-English heritage speakers' intuitions regarding the syllabification of Spanish words. More specifically, given different distributions in the two languages, we explored the patterning of diphthongs in a syllabification task. In the following sections we first present a description of diphthongs in English and Spanish with the relevant literature on bilingual syllabification and transfer effects, followed by the present experiment, its results, and its implications.

\section{BACKGROUND}

While the phonetic realization of diphthongs varies across dialects and registers, Spanish allows 14 canonical diphthong combinations. These consist of 6 falling diphthongs, in which a non-high vowel $([a, e, o])$ is followed by a tautosyllabic palatal or velar glide $([j, w]) ; 6$ rising diphthongs in which a non-high vowel is preceded by a palatal or velar glide in the same syllable; and two high vocoid combinations, 'iu' and 'ui', which are typically syllabified as rising diphthongs, [ju] and [wi] (Hualde, 2014). ${ }^{-}$Spanish has no restrictions on these combinations, as all vowels combine with both glides (although with varying frequency). Table 1 lists examples of Spanish words with each diphthong type. 


\section{Table 1}

Diphthongs in Spanish

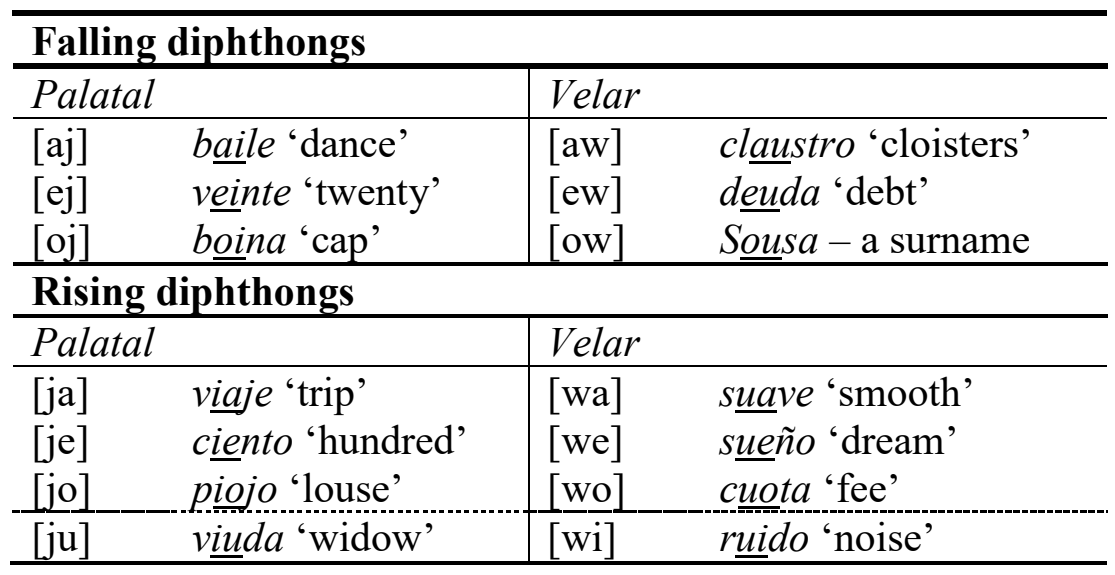

In contrast, the diphthong inventory of Standard American English is smaller and more phonotactically constrained. English has only 6 canonical diphthong combinations, of which all but one are falling diphthongs (Brinton \& Brinton, 2010). The possible diphthong combinations in English are listed in Table 2. $\stackrel{2}{ }$

Table 2

Diphthongs in English

\begin{tabular}{|c|c|}
\hline \multicolumn{2}{|c|}{ Falling diphthongs } \\
\hline Palatal & Velar \\
\hline high & [aw] \\
\hline hay & {$[\mathrm{ow}]$} \\
\hline boy & \\
\hline \multicolumn{2}{|c|}{ Rising diphthong } \\
\hline \multicolumn{2}{|l|}{ Palatal } \\
\hline [ju] & \\
\hline
\end{tabular}

Multiple observations can be made when comparing the diphthongs in the two languages. First, it is clear that the majority of Spanish diphthongs do not exist in English. Of the English falling diphthongs, only three of the five ([aj, oj, aw]) contrast with monophthongs in the language. For example, a native speaker of American English is aware of the distinction between [aj] and [a] in words such as kite [kajt] and cot [kat]. However, due to a natural diphthongization of the high-mid vowels, one rarely finds a "pure" [e] or [o] in English. This suggests that, unlike in the case of [aj], [oj], and [aw], native speakers of English may not be aware that they are producing two vocalic segments when pronouncing [ej] and [ow], as they never hear the monophthong counterpart. Another clear observation to be made is that English only has one rising diphthong, [ju]. The distribution of this diphthong is also restricted phonotactically. In American English, [ju] is disallowed after coronal consonants (Davis \& Hammond, 1995). For example, in most American 
dialects we find [ju] in words like music [mju:zik] and cute [kju:t], but only the monophthong in

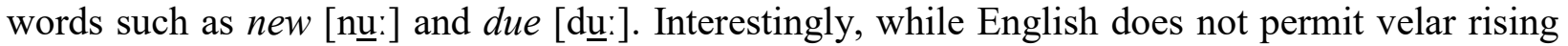
diphthongs, it does allow complex onsets with [w], as in the words thwart, twin, dwarf, swear, $\underline{s c h w a}$, and quote. Compare the syllable structures in English and Spanish in Figure 1.

Figure 1. Structure of [CwV] sequences in English and Spanish
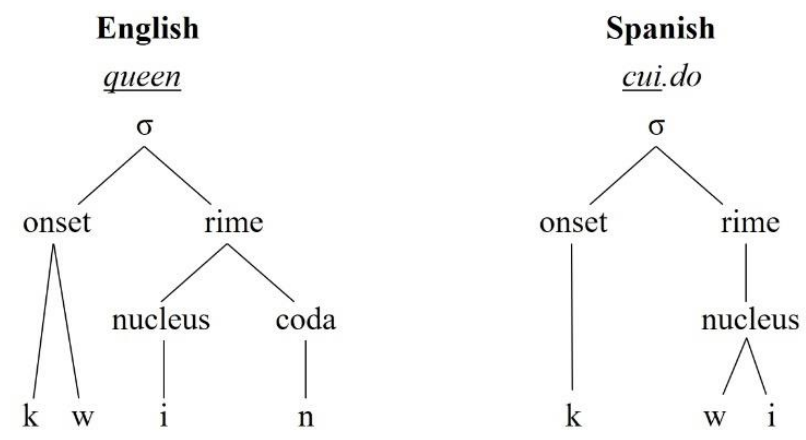

English assigns a prevocalic [w] to the onset with the preceding consonant. Spanish, by contrast, maps [w] into the nucleus as part of a rising diphthong. Thus, while the internal syllable structure is different in the two languages, there is a similarity between English and Spanish in that they both evidence tautosyllabic $\mathrm{CwV}$ sequences.

The different inventories and distributions of diphthongs in Spanish and English led Zárate-Sández (2011) to explore the syllabification intuitions of native speakers and L2 learners of Spanish. In his study, he questioned whether Spanish learners would have the same intuitions as native speakers regarding diphthongs and hiatus when syllabifying Spanish words, if cognates between the two languages (i.e., words with overlapping meaning and form, as in excellent and excelente) would behave differently than non-cognates, and if those intuitions would vary by proficiency level among the L2 speakers. In a paper-and-pencil task, native speakers and L2 learners from three levels of proficiency syllabified a list of 52 Spanish words. Thirty six words contained twovowel sequences, 17 of which were cognates. Participants also syllabified 16 monophthong distractors. All of the vowel sequences presented diphthongs in Spanish (i.e., no words contained vowel sequences for which hiatus was expected), and data were coded for accuracy of syllabification among the diphthongs. Results revealed no significant differences among the L2 learners, suggesting that their varying levels of proficiency did not influence their intuitions. They did, however, pattern significantly differently from the native speaker controls. The L2 participants syllabified diphthongs as hiatus (i.e., they broke the two segments of the diphthong into separate syllables) more often than native speakers. Furthermore, the results also identified a clear cognate effect among the stimuli, as learners were more likely to break diphthongs in Spanish when the word was a cognate with English. A closer look at the cognate items also revealed a clear hiatus effect, because words whose English translation contains a hiatus, such as die.ta $\sim$ di.et, were more often syllabified with hiatus than words whose English translation does not present hiatus, as in historia $\sim$ history. Among both cognate and non-cognate items, Zárate-Sández (2011) finds additional examples of apparent transfer from English phonotactics. Specifically, as one may predict, there is a much higher percentage of diphthong syllabifications for items containing falling diphthongs or diphthongs with a velar glide, as those combinations are permitted tautosyllabically 
in English (averages of $81 \%^{\frac{3}{3}}$ and $93 \%$ diphthongization, respectively). Words containing rising diphthongs with palatal glides were syllabified as diphthongs only $26 \%$ of the time. In sum, these findings suggest the cross-linguistic influence of phonotactic patterns from the L1 when native speakers of English syllabify words in their L2 Spanish (Carlisle, 2001; Major, 2008).

Returning our attention to heritage speakers, the results of Zárate-Sández (2011) pose an interesting question regarding transfer effects among populations for whom the L1 is not necessarily dominant. One might predict that the early exposure heritage speakers receive to their home language would lead to intuitions regarding syllabification that would mirror those of monolingual native speakers. However, one might also predict that their later experience with the societally dominant language may influence their intuitions leading to a different pattern of behavior. If the latter is the case, the direction of cross-linguistic influence is dominant language $\rightarrow$ heritage language (assuming the societally dominant language is also the speaker's dominant language), rather than the more traditional L1 $\rightarrow \mathrm{L} 2$. Recent work has begun to explore what has been called dominant language transfer, in which language dominance, rather than the order of acquisition, is the key factor in determining the directionality of transfer effects. However, as is the case with most heritage studies, the focus of this work has predominantly been in the realm of morphosyntax proper (Lee, 2014; Montrul, 2010) and the interfaces between morphosyntax and pragmatics, discourse, and semantics (Montrul, 2010; Montrul \& Ionin, 2010, 2012; Serratrice, Sorace, Filiaci, \& Baldo, 2009; Sorace, Serratrice, Filiaci, \& Baldo, 2009).

A series of studies by Sorace and Serratrice have suggested that certain interfaces are particularly vulnerable to interference and attrition among bilingual speakers. For example, in a set of forcedchoice grammaticality tasks, they tested heritage speakers of Italian living in the United Kingdom on their intuitions regarding the acceptability of overt and null subject pronouns (Sorace et al., 2009) and specific and generic plural noun phrases in Italian (Serratrice et al., 2009). In the latter study, their results showed that Italian-English bilinguals accepted bare plural nouns in generic contexts in Italian. As this structure is permitted in English (e.g., Dogs are domestic animals), but not in Italian (e.g., *Cani sono animali domestici), the heritage speakers' acceptance of these forms suggests that the heritage language has suffered transfer from the bilinguals' dominant societal language. Similarly, in the first task, the same population accepted a significantly higher percentage of overt pronouns in no-topic shift contexts in Italian than did native speaker controls. As Italian is a pro-drop language, the presence of overt pronouns often marks a shift in topic. The higher acceptance of overt pronouns in no-topic shift contexts in the experiment is attributed to the influence of the participants' knowledge of English, in which overt pronouns are required in both contexts. Montrul and Ionin $(2010,2012)$ reported similar results among Spanish-English heritage speakers, as Spanish also permits null subjects in no-topic shift contexts. Also focusing on pronominal usage and complement structure, Montrul (2010) tested the oral production and written acceptability of clitics among Spanish-English heritage speakers. While heritage speakers and monolinguals of Spanish performed similarly in their use of clitics in general and in clitic left dislocations, the heritage participants failed to pattern with monolingual speakers in their use of differential object marking. Spanish differs from English in that animate direct objects are preceded by the marker ' $a$ ', as in Hoy vi a Sebastián "Today I saw _ Sebastian." In an acceptability judgment task, heritage speakers were significantly more accepting of ungrammatical sentences missing $a$-marking and also produced unmarked animate objects in an oral production task. As 
English does not overtly mark animate objects, the absence of ' $a$ ' in heritage Spanish oral production and the higher acceptance of constructions that lack the marker are amenable to a view of transfer in which a dominant language influences intuitions and behavior in the heritage language.

With these studies in mind, we return to Zárate-Sández (2011). His study presents evidence of the transfer of syllabification intuitions for L2 speakers in which L1 English phonotactic patterns influence syllabification patterns in L2 Spanish. It also offers controlled comparisons that reveal cognate and hiatus effects for L2 learners. However, the analyses of rising and falling diphthongs and other patterns attributed to the phonotactic constraints of English were a posteriori observations. In the current study, we present an experiment that questions whether patterns similar to those identified among L2 learners will also surface in a heritage population. With controlled comparisons among the diphthongs, drawn from the diverging phonotactic patterns in the two languages, and a new population, we may learn more about heritage phonology, specifically at the level of the syllable, and the role of language dominance in cross-linguistic influence.

\section{MeThodology}

This experiment compares the metalinguistic intuitions of heritage and functionally monolingual speakers of Spanish when syllabifying words in their first language. The critical manipulation consists of Spanish words containing rising and falling diphthongs, controlled for comparison with English phonotactic patterns. Additionally, stimuli were controlled for cognate status and the hiatus status of their English translations (Zárate-Sández, 2011).

\section{Participants}

Two groups of Spanish speakers participated in this experiment. The first, and the principal focus of this study, consisted of 29 heritage speakers of Spanish. All were college undergraduates residing in Los Angeles, with an average age of 20. The second group comprised 29 functionally monolingual speakers of Spanish from southern Spain who served as a control comparison to the heritage speakers. These participants were undergraduate students at a university in eastern Andalusia, with an average age of $22 .^{4}$ The heritage speakers completed a language history questionnaire modeled after Montrul (2012b), which elicited information on participants' language learning history, self-rated proficiency, and language use, and from which the following demographic information derives. All participants were born in the U.S., except for three who were born in Mexico and one who was born in Venezuela. Participants may be considered bilinguals with early exposure to Spanish, as all reported having begun to learn the language before the age of 5, with the exception of one participant who reported beginning Spanish at age 10. $\frac{5}{\text { Most }}$ participants also report beginning to learn English from birth to age 5, although four report having begun slightly later in childhood at ages 6, 7, 9, and 11. While they were all exposed to Spanish very early in life, their later linguistic experience was predominantly in English. All attended elementary schools and high schools in the U.S. in which English was the primary language of instruction. Participants rated their overall language ability in the two languages on a scale of 1-5 as seen in Table 3. 
Table 3

Participant Self-ratings of Language Ability

\begin{tabular}{l|l|l|l|l|l}
\hline \multicolumn{2}{l}{ Responses } & \multicolumn{2}{l}{ In English } & \multicolumn{2}{c}{ In Spanish } \\
\hline 1 & understand but cannot speak & 0 & $0 \%$ & 0 & $0 \%$ \\
\hline 2 & understand and can speak with great difficulty & 0 & $0 \%$ & 0 & $0 \%$ \\
\hline 3 & understand and speak but with some difficulty & 1 & $3 \%$ & 9 & $31 \%$ \\
\hline 4 & understand and speak comfortably, with little difficulty & 5 & $17 \%$ & 13 & $45 \%$ \\
\hline 5 & understand and speak fluently like a native speaker & 23 & $79 \%$ & 7 & $24 \%$ \\
\hline & Total & 29 & $100 \%$ & 29 & $100 \%$ \\
\cline { 2 - 7 } & Average score on a 1-5 scale: & $\mathbf{4 . 7 6}$ & & $\mathbf{3 . 9 3}$ & \\
\hline
\end{tabular}

Heritage speakers on average rate their language skills higher in English than in Spanish (4.76 versus 3.93 out of 5.00). As concerns their current use of Spanish, 86\% of the participants report using Spanish with their mother and/or father, but only 14\% report using the language with siblings. When asked which language they use with Spanish-speaking friends, no one reported using only Spanish. With their friends, $48 \%$ responded that they only speak English, and 52\% use a mixture of both languages. These self reports of age of acquisition, language proficiency, and language use suggest that English is their stronger and more dominant language. Given the focus of this study, the heritage speakers were also asked if they had previously learned any rules about how to divide words into syllables in Spanish. Twenty two of the 29 participants responded yes. Arguably, this instruction should help the heritage group to syllabify diphthongs in the expected canonical fashion.

\section{Procedure and Stimuli Design}

In a paper-and-pencil task, participants divided 80 words in Spanish into syllables using slashes. They were instructed to divide the words carefully, but not to spend too much time on any given word, and not to revise or change their answers. They were told to rely on their first intuitions. To begin the experiment, participants first divided three words together with the investigator as practice trials to ensure that they understood the procedure. They then proceeded to syllabify the 80 items. After completion of the experiment, participants completed the language history questionnaire.

The stimuli for the syllabification task were chosen carefully to produce comparisons between English and Spanish phonotactic constraints. Forty Spanish words with diphthongs were chosen to produce four critical comparisons. First, to test for a cognate effect among the syllabification patterns, the diphthong stimuli were divided into two groups, one of 18 cognates with English, such as historia history, and a second group of 22 non-cognates, such as aceite $\sim$ oil. Second, the cognate items were further divided into two groups based on the syllable structure of their English translations. The first group contained seven items whose English counterpart presents hiatus where the Spanish word has a diphthong, as in material materi.al. The second group consisted of 11 words whose English translation does not present hiatus, e.g., historia $\sim$ history. The third critical comparison was between rising and falling diphthongs, given their disparate 
distributions in the two languages. Among the 40 words with diphthongs, 24 stimuli contained rising diphthongs, such as viaje 'trip' and sueño 'dream', and a set of 16 contained falling diphthongs, as in baile 'dance' and deuda 'debt'. Lastly, also due to different licensing in English and Spanish, the diphthong stimuli were further controlled to permit comparisons between 24 items with palatal glides and 16 words with velar glides. Thus a category of words such as viaje and baile, with palatal glides, could be compared to words like sueño and deüda, containing velar glides. $\underline{\underline{6}}$

In addition to the principal diphthong stimuli, a set of 24 words with expected hiatus were also included. These words served two purposes. First, they added to the cognate/non-cognate comparison in the experiment. Cognates with hiatus, like re.alidad $\sim$ reality and muse.o $\sim$ museum appeared with non-cognate items, such as tra.er $\sim$ bring and alde.a $\sim$ village. Second, and more importantly, the expected hiatus stimuli discouraged parsing strategies among the participants when they encountered sequences of two orthographic vowels. If no hiatus stimuli had been included, all sequences of two vowels in the experiment would have been syllabified always as a diphthong. If stimuli containing expected hiatus sequences are included, however, participants will be presented with multiple words containing vowel sequences that should be syllabified into the same syllable forming a diphthong, and others that should be syllabified as hiatus into separate syllables. In this way, it was not possible for participants to know which were which, without relying on their intuitions regarding the proper syllabification. The inclusion of these items addresses a limitation acknowledged in Zárate-Sández (2011), in which all vowel sequences were expected to yield a diphthong syllabification. Finally, an additional 16 filler items were included in the study. These stimuli contained only monophthong vowels, as in presidente, camisa, and famoso. Table 4 summarizes the 80 items used in the task.

\section{Table 4}

Summary of Experimental Items

\begin{tabular}{|c|c|c|c|c|}
\hline Word Type & Quantity (80) & & Examples & \\
\hline \multirow{3}{*}{ Diphthongs } & \multirow{3}{*}{40} & \multirow{3}{*}{$\begin{array}{c}\text { Rising } \\
\text { Falling }\end{array}$} & Palatal Glides & Velar Glides \\
\hline & & & viaje & sueño \\
\hline & & & baile & deuda \\
\hline Hiatus & 24 & \multicolumn{3}{|c|}{ re.alidad, muse.o $\sim$ tra.er, alde.a } \\
\hline Fillers & 16 & \multicolumn{3}{|c|}{ presidente, camisa, famoso } \\
\hline
\end{tabular}

Note. Additional comparisons: cognate/non-cognate, English translation with/without hiatus.

\section{Predictions}

If the heritage speakers' knowledge of English phonotactic patterns influences their intuitions on Spanish syllabification, we can make certain predictions regarding how they will perform when syllabifying words in their heritage language. These predictions derive from the controlled stimuli set that was developed to allow for certain comparisons. Regarding diphthong syllabification, we can make four predictions. The first two are interdependent and derive from Zárate-Sández (2011), in which the restrictions on syllable structure of the dominant L1 were found to be manifest in the syllabification of words in the L2. In his study, a hiatus effect among English translations of 
Spanish words motivated a more general cognate effect in the L2 data. We predict a replication of these two patterns, but in a different direction: (1) Spanish-English heritage speakers will break diphthongs into hiatus more often in cognates than non-cognates, and (2) Spanish-English heritage speakers will break diphthongs into hiatus more often when the English translation presents hiatus in the same position. In the case of our participants, the arguable dominance of English among the heritage population should influence their intuitions regarding syllabification in their heritage Spanish. The third and fourth predictions are based on the distribution of diphthongs in English and are also interconnected. We predict that (3) Spanish-English heritage speakers will break diphthongs into hiatus more often in rising diphthongs than in falling diphthongs. As all but one diphthong in English are falling diphthongs, it is plausible that any cross-linguistic influence will have a greater effect on the rising diphthongs that English does not permit. Subsequently, if (3) proves true, we expect that (4) Spanish-English heritage speakers will also break diphthongs into hiatus more often when a rising diphthong contains a palatal glide than when it contains a velar glide. This final prediction is due to the subsyllabic structures illustrated in Figure 1. While English does not license rising diphthongs with a velar glide, $/ \mathrm{w} /$ is permitted in prevocalic position in the same syllable as the vowel. Therefore, if there is transfer from English, participants should be less likely to break a rising diphthong containing a velar glide, because the velar glide may be parsed into the onset in English. In contrast, palatal glides may not be syllabified into the onset in the same way, which we predict will lead to more cases of hiatus for words containing palatal glides. As the monolingual control group does not speak English (at least to a level of fluency that would predict transfer of phonotactic constraints), we predict no significant effects among the native speakers for any of the previously described comparisons. Lastly, with respect to the expected hiatus stimuli, we do not predict any differences between the heritage and monolingual participant groups, as both English and Spanish permit heterosyllabic vowel sequences.

\section{Data Coding}

All vocoid sequences were coded for diphthong syllabification. As participants marked syllable divisions by means of a slash, any two consecutive vocalic segments that were not divided by a slash were considered a diphthong and were coded as ' 1 '. If vocalic segments were divided by a slash, this indicated hiatus, and the item was coded as ' 0 '. For example, if a participant syllabified the word iglesia 'church' as follows: $\mathrm{i} / \mathrm{g} 1 \mathrm{e} / \mathrm{s}$ i a, the item was coded as ' 1 ', because the final syllable contains a diphthong. However, if a participant broke the final diphthong into hiatus, as in: $\mathrm{i} / \mathrm{g} \mathrm{l} \mathrm{e} / \mathrm{s} \mathrm{i} / \mathrm{a}$, then the stimulus received a ' 0 ', because the syllabification that was assigned to the word contains no diphthongs. Filler items, which included no vocoid sequences, were also coded as ' 0 '. A total 4,640 items were coded for analysis. In this way, we were able to assess the average percentage of diphthongization among participants for all comparison categories. Upon completion of coding, each critical comparison was submitted to repeated-measures ANOVAs.

\section{RESULTS AND DISCUSSION Syllabification Patterns}

A summary breakdown of the percentage of diphthong syllabification in all conditions for both participant groups can be seen in Table 5 . 


\section{Table 5}

Summary of Syllabification Patterns - Percentage of Diphthong Syllabification by Condition

\begin{tabular}{l|l|l|l|l|l|l|l|l}
\hline \multicolumn{1}{l}{ Participants } & \multicolumn{10}{c}{ Condition } \\
\hline & Cognates & $\begin{array}{l}\text { Non- } \\
\text { cognates }\end{array}$ & $\begin{array}{l}\text { English- } \\
\text { hiatus }\end{array}$ & $\begin{array}{l}\text { English- } \\
\text { nonhiatus }\end{array}$ & $\begin{array}{l}\text { Rising } \\
\text { diphthongs }\end{array}$ & $\begin{array}{l}\text { Falling } \\
\text { diphthongs }\end{array}$ & $\begin{array}{l}\text { Palatal } \\
\text { glides }\end{array}$ & $\begin{array}{l}\text { Velar } \\
\text { glides }\end{array}$ \\
\hline Heritage & $59 \%$ & $67 \%$ & $59 \%$ & $90 \%$ & $77 \%$ & $86 \%$ & $74 \%$ & $83 \%$ \\
\hline Monolingual & $50 \%$ & $53 \%$ & $63 \%$ & $67 \%$ & $68 \%$ & $65 \%$ & $69 \%$ & $67 \%$ \\
\hline
\end{tabular}

\section{Statistical Analyses}

Four $2 \times 2$ analyses of variance compared heritage speakers and monolingual speakers and the four conditions described above. The first, an ANOVA comparing cognates to non-cognates, found a significant main effect of cognate status, $F(1,56)=19.06, p<.01$, a significant main effect of participant type, $F(1,56)=5.19, p<.05$, and a significant interaction of cognate status and participant type, $F(1,56)=5.58, p<.05$. A second analysis comparing those cognates whose English translation contains hiatus with those whose translation does not present hiatus found a significant main effect of hiatus status, $F(1,56)=48.86, p<.01$, no significant effect of participant type, $F(1,56)=2.52, p>.11$, and a significant interaction of hiatus status and participant type, $F(1,56)=26.23, p<.01$. The third comparison tested the patterning of rising diphthongs versus falling diphthongs and found no significant main effect of diphthong type, $F(1$, $56)=2.17, p>.14$, a significant main effect of participant type, $F(1,56)=5.73, p<.05$, and a significant interaction of diphthong type and participant type, $F(1,56)=8.11, p<.01$. The final ANOVA compared rising diphthongs with palatal glides to those with velar glides and found no significant main effect of glide type, $F(1,56)=2.32, p>.13$, no significant main effect of participant type, $F(1,56)=3.02, p>.08$, and a significant interaction of glide type and participant type, $F(1,56)=6.13, p<.05$.

When interpreting these results, it is crucial to note that differences in behavior between heritage speakers and monolingual speakers when presented with each stimulus pairing is revealed in the interactions between the main effects. Main effects test whether one independent variable has an effect on the dependent variable, ignoring any other independent variables. Therefore, the main effects of participant type in our analyses examine whether the syllabification patterns of heritage speakers and monolingual controls differ in a given condition in general, without considering the behavior of the two stimulus types involved. Similarly, the main effects of cognate status, hiatus status, diphthong type and glide type reflect differences between the word types in each condition irrespective of participant group. We therefore are not concerned by the occasional lack of significant main effects in our data. It is in the interactions between the effects that we see how our two populations are reacting to the critical conditions in the experiment. In all cases, the interactions between participant type and stimulus type were significant. Pairwise comparisons are illustrated more clearly in Figures 2 and 3, which list the average percentage of diphthongization for each type of stimulus by participant group and identify significant differences between them. 
Figure 2. Percentage of diphthong syllabification by category for heritage speakers

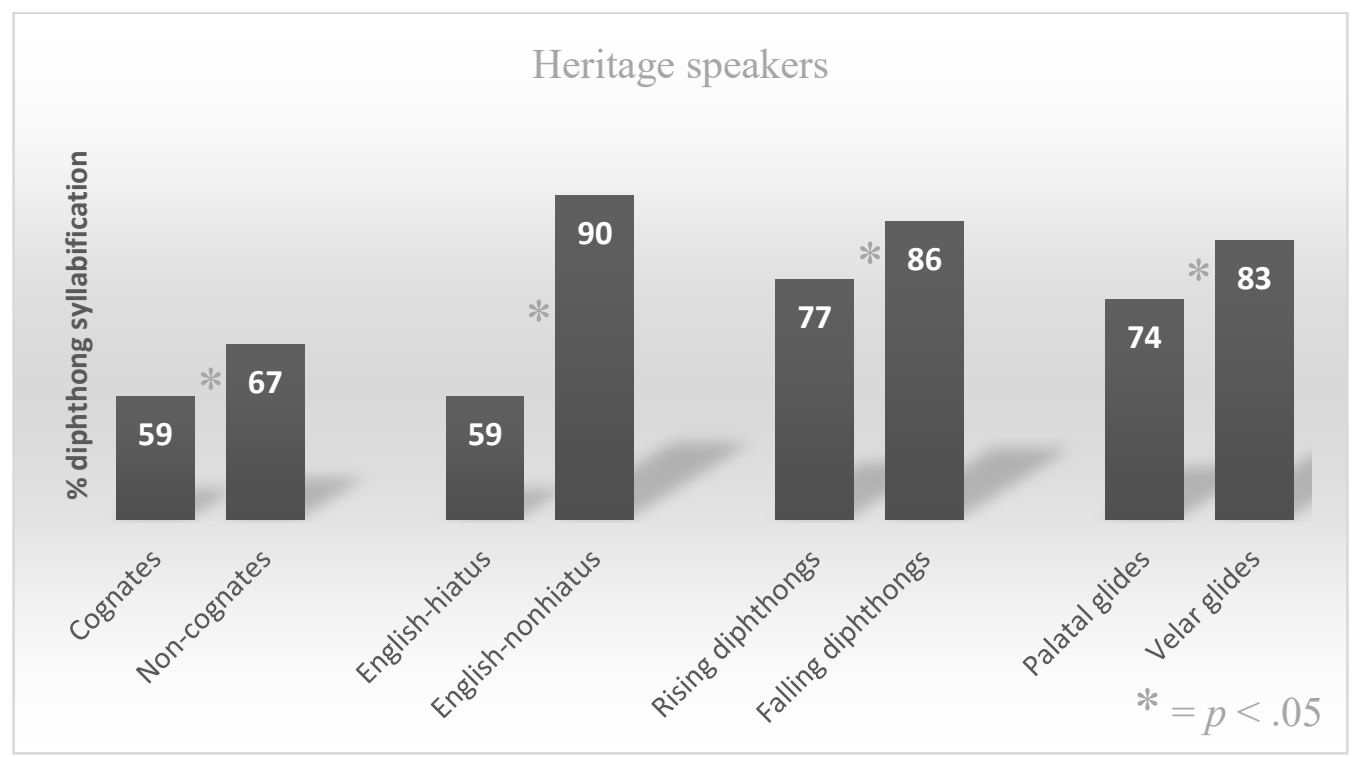

Figure 3. Percentage of Diphthong Syllabification by Category for Monolingual Speakers

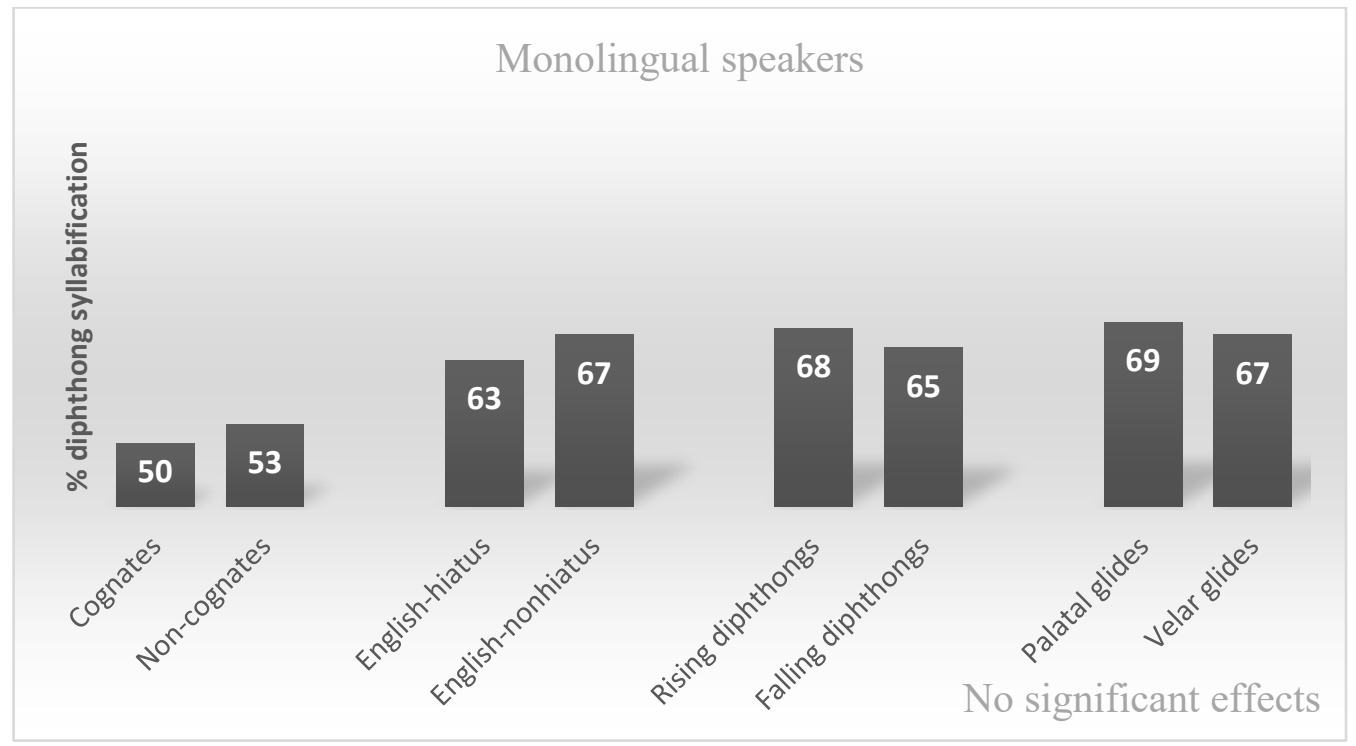

One final analysis was also run to test the patterning of the words for which hiatus was expected. A one-way ANOVA comparing heritage and monolingual speakers' syllabification of expected hiatus stimuli found no significant main effect of participant type, $F(1,56)=2.08, p>.15$. This result supports our prediction that heritage speakers and monolingual controls would not differ in their syllabification of the expected hiatus stimuli. Heritage and monolingual speakers syllabified these items as diphthongs only $34 \%$ and $26 \%$ of the time, respectively. 


\section{Heritage Speaker Performance}

Figure 2 illustrates the results of four critical comparisons among phonotactic constraints in Spanish and English. When syllabifying words in their home language, the behavior of heritage speakers of Spanish suggests the influence of English on their intuitions regarding syllabification in all four categories that were tested. First, diphthongs in cognates were syllabified as diphthongs $59 \%$ of the time, as compared to a $67 \%$ diphthongization rate among non-cognates. This suggests that cognates like material, a word with more obvious phonological and orthographic overlap with English, were syllabified with hiatus significantly more often than words like aceite, a non-cognate whose phonological and orthographic properties are less similar to English, and thus arguably induce less cross-linguistic interference. This result supports our first prediction that SpanishEnglish heritage speakers would break diphthongs into hiatus more often in cognates than in noncognates.

The second comparison concerns the patterning of the two types of cognates. In the first, the English translation presents hiatus where the Spanish word contains a diphthong, as in material materi.al. In the second, the English translation does not contain two vowels in hiatus, historia $~$ history. This comparison was performed to test the reason for the cognate effect in our data (and in Zárate-Sández, 2011). Arguably, if the participants are transferring phonotactic knowledge from their dominant language into their less dominant language, contexts in which the patterns between the two languages conflict should result in larger differences in the data. This is the result that we found here. The two effects are interdependent. Generally, the similarities in properties among cognates cause more errors in syllabification patterns. However, more specifically, a significantly lower rate of diphthongization is found among those stimuli whose English translations presents hiatus where Spanish requires a diphthong. Among cognates with a hiatus in their English translation, heritage speakers syllabified the items with diphthongs only $59 \%$ of the time. In contrast, we see a strong effect in the opposite direction for those cognates whose English translation presents a diphthong (e.g., feudal [few.ðal] feudal [fju...əl]) or a monophthong (historia $\sim$ history) in the same position, facilitating a monosyllabic syllabification pattern. For these items, heritage speakers assigned a diphthong syllabification $90 \%$ of the time. This inhibitory effect among hiatus translations and facilitatory effect among diphthong or monophthong translations supports our second prediction.

The patterning of the rising and falling diphthongs in the heritage speaker data is subtler, but nonetheless statistically significant. Here, we see that rising diphthongs are syllabified as diphthongs $77 \%$ of time, compared to an $86 \%$ diphthong syllabification rate for falling diphthongs. Recall that five of the six diphthongs in English are falling diphthongs. We therefore predicted that heritage speakers, if they are transferring phonotactic patterns from English, would be more likely to accept diphthong syllabifications for Spanish falling diphthongs than for Spanish rising diphthongs, as the only rising diphthong in English is [ju]. This is indeed the pattern borne out in the data, which supports our third prediction.

The final comparison from Figure 2 is a similarly subtle pattern between the palatal and velar glides in rising diphthongs. Given that English permits prevocalic velar glides in the onset of a syllable, tautosyllabic [CwV] sequences are permitted in both languages. Prevocalic palatal glides, on the other hand, may not form part of a complex onset. The only permissible syllabification of 
$[\mathrm{CjV}]$ in English is found in the sole rising diphthong [ju] (Davis \& Hammond, 1995). Furthermore, as mentioned above, [ju] may not appear in Standard American English following coronal consonants due to a homorganicity constraint. Therefore, we predicted that, if heritage speakers transfer phonotactic knowledge from English when syllabifying in Spanish, they would break rising diphthongs into hiatus more often for palatal glides than for velar glides, as a result of the widespread licensing of $/ \mathrm{w} /$ in complex onsets and the extremely restricted presence of prevocalic $/ \mathrm{j} /$ in English. Figure 2 shows that rising diphthongs containing palatal glides were syllabified as diphthongs $74 \%$ of the time. Rising diphthongs with velar glides, on the other hand, received a significantly higher rate of diphthongization, $83 \%$. This result offers support for our fourth prediction.

Viewed together, these four significant results reveal a general transfer effect from English into Spanish among Spanish-English heritage speakers. This is the case, despite the fact that most participants had previously been taught how to syllabify words in Spanish. This instruction should arguably have helped the participants syllabify the expected diphthongs in the canonical way. The fact that English patterns nonetheless appear to influence their intuitions in Spanish strengthens the present results. These findings, in one sense, replicate a pattern observed in the L2 literature in which phonotactic constraints of the native language are manifest in late learners' intuitions regarding possible syllable boundaries in their second language. However, in our data, the direction of influence is not L1 $\rightarrow$ L2. Instead, we see that the phonology of the home language, rather than exerting its influence on an L2, instead receives the transfer of phonotactic restrictions from a societally dominant second language.

\section{Monolingual Performance}

Turning our attention to the monolingual controls, as seen in Figure 3, no significant differences were found for monolingual speakers of Spanish. This is the predicted pattern, as one would not expect any transfer effects from English among participants who do not speak the language with sufficient fluency. It is noteworthy, however, that the monolingual speakers do not perform at ceiling in their own language. The first comparison between cognates and non-cognates is the predicted pattern, given that this particular analysis includes both diphthong and expected hiatus stimuli. As diphthongization hovers around 50\%, this suggests that the participants are performing at chance. However, the remaining comparisons were conducted only on diphthong stimuli, which makes the monolingual behavior less expected. It is difficult to establish conclusively why the native speakers performed so badly. The control group assigned a diphthong syllabification between $63-69 \%$ of the time for all diphthong stimuli. In this sense, they clearly treated all diphthong items the same, regardless of the structure of the English translation, or the type or positioning of the glide. What is interesting is the anti-diphthong pattern present in the data, especially given the general anti-hiatus tendency in Spanish (Colantoni \& Hualde, 2016; Garrido, 2013; Souza, 2010). For example, it is well established in the literature that the normative pronunciation of vowel sequences beginning with mid vowels, such as teatro 'theater' and poeta 'poet', is one of hiatus (cf. Quilis, 1993, among many others). However, there is a tendency among Spanish speakers to reduce hiatus among such sequences, resulting in a continuum of forms ranging between clear hiatus, e.g., [te.a.tro] and [po.e.ta], to full diphthongization, e.g., [tja.tro] and [pwe.ta] (Hualde, 2014; Navarro Tomás, 1918). It is thus unexpected to find a higher degree of hiatus for expected diphthongs, rather than the reverse. 
One possible interpretation of the monolingual data, and one that Zárate-Sández (2011) adopts in his paper to account for similar results in his study, is that there are differences among Spanish dialects concerning the syllabification of some words containing $\mathrm{iV}$ and $\mathrm{uV}$ sequences, in which the high vowels surface as syllabic, rather than the traditional nonsyllabic glide forms (Hualde, 1999; Hualde \& Prieto, 2002; Simonet, 2005; Cabré \& Prieto, 2006). Zárate-Sández (2011) argues that the heterogeneity of his native-speaker participant group may have included speakers for whom words like cliente 'customer' or situado 'located' present hiatus, [kli.en.n.te] and [si.tu.a.ðo], rather than the diphthong syllabifications [kljen.te] and [si.twa.ðo]. These intuitions could lead to what would appear to be an anti-diphthong tendency among a subset of words. However, we argue that this is not likely the case for our data. First, our native speakers come from southern Spain, where the non-canonical syllabification pattern, to our knowledge, has not been observed. Second, if it were the case that our native speaker group included speakers with such intuitions, we would expect to see higher cases of hiatus among what we have classified as rising diphthongs, as the observed pattern concerns $\mathrm{iV}$ and $\mathrm{uV}$ sequences. Falling diphthongs would arguably remain unaffected. In our data, however, we do not see a higher degree of diphthongization for falling diphthong stimuli than for rising diphthong items. On the contrary, descriptively, rising diphthongs are syllabified more often as diphthongs than falling diphthongs, but this difference is not statistically significant. We, therefore, attribute the high rate of error among native speakers to the nature of the syllabification task.

\section{Metalinguistic Intuitions}

It is important to note that this study taps metalinguistic intuitions regarding syllabification, not the natural production of these forms. It is certainly not the case that native speakers of Spanish break diphthongs into hiatus over $30 \%$ of the time when they pronounce words containing them. It is much more likely that the orthographic nature of the experiment, in which glides and high vowels are indistinguishable in their written forms, may have led to higher levels of hiatus. Similarly, participants may have slowed their inner voice substantially as they sounded out words in order to syllabify them. For example, it is quite possible that a speaker may pronounce the word ingenua 'naïve', which contains the diphthong [wa], as in..ge..nu..a in especially slow speech. In so doing, what is normally pronounced as a glide becomes a vowel and is assigned its own syllable. If this is the case, then the uncontrolled rate of inner speech in this study added noise to the data. It is essential to observe, however, that this noise affects all stimulus types, and does not diminish the findings of clear transfer effects among the heritage speaker data, because those effects pattern exactly as one would predict given English phonotactics. It suggests instead that metalinguistic intuitions regarding syllabification are hazy, and, simply put, a paper-and-pencil syllabification task is difficult, for native and non-native speakers alike.

\section{CONCLUSIONS}

The present study tested whether Spanish-English heritage speakers and monolingual speakers of Spanish would behave differently when syllabifying words in their native language. The results of a syllabification task suggest that the phonotactic patterns of a (societally) dominant language can influence metalinguistic intuitions regarding syllabification in the heritage language. This is demonstrated in the different patterns observed between heritage speakers and monolingual speakers in a task that permitted carefully controlled comparisons of Spanish and English 
(sub)syllabic phonotactic constraints. We identified cross-linguistic influence in four critical comparisons: heritage speakers broke diphthongs into hiatus more often among cognates than among non-cognates, among cognates whose English translation presented hiatus more often than among those that did not, among rising diphthongs more often than among falling dipthongs, and among rising diphthongs containing palatal glides more often than among those containing velar glides. Monolingual speaker data evidenced no differential patterning in any category. These effects in combination are indicative of the transfer of phonotactic restrictions from the dominant phonology onto the heritage phonology within a heritage speaker population, replicating and extending patterns already observed for L2 populations, but motivated by language dominance rather than order of acquisition.

These findings offer further analysis of the phonology of heritage speakers, an understudied subfield, by showing differential behavior between two communities of L1 Spanish speakers, monolinguals and early bilinguals, specifically at the suprasegmental level. To our knowledge, no studies have yet addressed syllabification among heritage speaker populations. The current experiment, while metalinguistic and therefore tentative in nature, is a first step in exploring untested areas of heritage phonology between the recent segmental studies and suprasegmental work on intonation and stress perception. Future work of a behavioral nature would add support to these results. The findings also add to the growing body of literature on language transfer from a dominant to a heritage language. While previous literature exploring dominant language transfer has focused primarily on morphosyntax proper and the morphosyntax-discourse, morphosyntaxpragmatics, and morphosyntax-semantics interfaces (Lee, 2014; Montrul \& Ionin, 2010, 2012; Sorace, 2004; Sorace \& Serratrice, 2009), the patterns revealed in the present study suggest that heritage phonology, long held to be less vulnerable to attrition or transfer, is indeed open to influence from other languages learned or strengthened later in life.

\section{ACKNOWLedgments}

Special thanks are due to Samuel Wylie for his attentive assistance in data collection for this study. We would also like to thank the audiences of the III Symposium on Spanish as a Heritage Language, CASPSLaP 2016, and the XIV Encuentro Internacional de Lingüística en el Noroeste de México for their thoughts and comments. All remaining errors are our own.

\section{REFERENCES}

Alvord, S. M., \& Rogers, B. M. A. (2014). Miami-Cuban Spanish vowels in contact. Sociolinguistic Studies, 8(1), 139-170.

Amengual, M. (2016). Acoustic Correlates of the Spanish Tap-Trill Contrast: Heritage and L2 Spanish Speakers. Heritage Language Journal, 13(2), 88-112.

Au, T. K., Oh, J. S., Knightly, L. M., Jun, S., \& Romo, L. F. (2008). Salvaging a childhood language. Journal of Memory and Language, 58, 998-1011.

Benmamoun, E., Montrul, S., \& Polinsky, M. (2010). White paper: Prolegomena to heritage linguistics. University of Illinois at Urbana-Champaign and Harvard University. Retrieved from http://scholar.harvard.edu/mpolinsky/publications/white-paper-prolegomena-heritage$\underline{\text { linguistics }}$ 
Boomershine, A. (2013). The perception of English vowels by monolingual, bilingual, and heritage speakers of Spanish and English. In. C. Howe, S. E. Blackwell, \& M. Lubbers Quesada (Eds.), Selected Proceedings of the 15th Hispanic Linguistics Symposium (pp. 103-118). Somerville, MA: Cascadilla Proceedings Project.

Brinton, L. J., \& Brinton, D. M. (2010). The Linguistic structure of modern English. Amsterdam, The Netherlands: John Benjamins.

Cabré, T., \& Prieto, P. (2006). Exceptional hiatuses in Spanish. In F. Martínez-Gil \& S. Colina (Eds.), Optimality-Theoretic studies in Spanish phonology (pp. 205-238). Amsterdam, The Netherlands: John Benjamins.

Carlisle, R. S. (2001). Syllable structure universals and second language acquisition. International Journal of English Studies, 1(1), 1-19.

Colantoni, L., Cuza, A., \& Mazzaro, N. (2016) Task-related effects in the prosody of Spanish heritage speakers and long-term immigrants. In M. E. Armstrong, N. Henriksen, \& M. del Mar Vanrell (Eds.), Intonational grammar in Ibero-Romance: Approaches across linguistic subfields (pp. 3-23). Amsterdam, The Netherlands: John Benjamins.

Colantoni, L., \& Hualde, J. I. (2016). Conditions on front mid-vowel gliding in Spanish. In R. A. Núñez Cedeño (Ed.), The syllable and stress: Studies in honor of James W. Harris (pp. 3-27).

Davis, S., \& Hammond, M. (1995). On the status of onglides in American English. Phonology, $12(2), 159-182$.

Garrido, M. (2013). Hiatus resolution in Spanish: Motivating forces, constraining factors, and research methods. Language and Linguistics Compass, 7(6), 339-350.

Harris, M. J., \& Gries, S. Th. (2011). Measures of speech rhythm and the role of corpus-based word frequency: A multifactorial comparison of Spanish(-English) speakers. International Journal of English Studies, 11(2), 1-22.

Henriksen, N. (2015). Acoustic analysis of the rhotic contrast in Chicagoland Spanish: An intergenerational study. Linguistic Approaches to Bilingualism, 5(3), 285-321.

Hualde, J. I. (1999). Patterns in the lexicon: Hiatus with unstressed high vowels in Spanish. In J. Gutiérrez-Rexach, and F. Martínez-Gil (Eds.), Advances in Hispanic linguistics: Papers from the $2^{\text {nd }}$ Hispanic Linguistics Symposium (pp. 182-197). Somerville, MA: Cascadilla Press.

Hualde, J. I. (2014). Los sonidos del español. Cambridge: Cambridge University Press.

Hualde, J. I., \& Prieto, M. (2002). On the diphthong/hiatus contrast in Spanish: Some experimental results. Linguistics, 40(2), 217-234.

Kim, J. (2015). Perception and production of Spanish lexical stress by Spanish heritage speakers and English L2 learners of Spanish. In E. W. Willis, P. M. Butragueño, \& E. Herrera Zendejas (Eds.), Selected proceedings of the 6th Conference on Laboratory Approaches to Romance Phonology (pp. 106-128). Somerville, MA: Cascadilla Proceedings Project.

Lee, T. (2014). Dominant language transfer in the comprehension of L2 learners and heritage speakers. International Journal of Applied Linguistics, 1-24.

Major, R. C. (2008). Transfer in second language phonology. In J. G. Hansen Edwards, \& M. L. Zampini (Eds.), Phonology and Second Language Acquisition (pp. 63-94). Amsterdam, The Netherlands: John Benjamins.

Montrul, S. (2010). Dominant language transfer in adult second language learners and heritage speakers. Second Language Research, 26(3), 293-327. 
Montrul, S. (2012a). The grammatical competence of Spanish heritage speakers. In S. M. Beaudrie $\&$ M. Fairclough (Eds.), Spanish as a heritage language in the United States (pp. 101-120). Washington, DC: Georgetown University Press.

Montrul, S. (2012b). Bilingual background questionnaire for Spanish/English speakers. Retrieved from http://www.nhlrc.ucla.edu/nhlrc/data/questionnaires

Montrul, S., \& Ionin, T. (2010). Transfer effects in the interpretation of definite articles by Spanish heritage speakers. Bilingualism: Language and Cognition, 13(4), 449-473.

Montrul, S., \& Ionin, T. (2012). Dominant language transfer in Spanish heritage speakers and second language learners in the interpretation of definite articles. The Modern Language Journal, 96(1), 70-94.

Navarro Tomás, T. (1918). Manual de pronunciación española. Madrid, Spain: Centro de Estudios Históricos.

Pascual y Cabo, D. (2013). Knowledge of gustar-like verbs in Spanish heritage speakers. In J. Cabrelli Amaro, T. Judy, \& D. Pascual y Cabo (Eds.), Proceedings of the 12th Generative Approaches to Second Language Acquisition Conference (GASLA 2013) (pp. 162-169). Somerville, MA: Cascadilla Proceedings Project.

Quilis, A. (1993). Tratado de fonética y fonología españolas. Madrid, Spain: Editorial Gredos.

Rao, R. (2014). On the status of the phoneme /b/ in heritage speakers of Spanish. Sintagma, 26, $37-54$.

Rao, R. (2015). Manifestations of /bdg/ in heritage speakers of Spanish. Heritage Language Journal, 12(1), 48-74. Available from http://www.heritagelanguages.org

Rao, R. (2016). On the nuclear intonational phonology of heritage speakers of Spanish. In D. Pascual y Cabo (Ed.), Advances in Spanish as a heritage language (pp. 51-80).

Rao, R., \& Ronquest, R. (2015). The heritage Spanish phonetic/phonological system: Looking back and moving forward. Studies in Hispanic and Lusophone Linguistics, 8(2), 403-414.

Roca, I. (2016). Gliding ghosts or ghostly glides, and does it matter which? In R. A. Núñez Cedeño (Ed.), The syllable and stress: Studies in honor of James W. Harris (pp. 51-104).

Ronquest, R. E. (2013). An acoustic examination of unstressed vowel reduction in heritage Spanish. In. C. Howe, S. E. Blackwell, \& M. Lubbers Quesada (Eds.), Selected proceedings of the 15th Hispanic Linguistics Symposium (pp. 157-171). Somerville, MA: Cascadilla Proceedings Project.

Serratrice, L., Sorace, A., Filiaci, F., \& Baldo, M. (2009). Bilingual children's sensitivity to specificity and genericity: Evidence from metalinguistic awareness. Bilingualism: Language and Cognition, 12(2), 239-257.

Sorace, A. (2004). Native language attrition and developmental instability at the syntax-discourse interface: Data, interpretations and methods. Bilingualism: Language and Cognition, 7(2), $143-145$.

Simonet, M. (2005). Prosody and syllabification intuitions of [CiV] sequences in Spanish and Catalan. In S. Frota, M. Vigário, \& M. J. Freitas (Eds.), Prosodies: With special reference to Iberian languages (pp. 247-267). Berlin, Germany: Mouton de Gruyter.

Sorace, A. \& Serratrice, L. (2009). Internal and external interfaces in bilingual language development: Beyond structural overlap. International Journal of Bilingualism, 13(2), 195210.

Sorace, A., Serratrice, L., Filiaci, F., \& Baldo, M. (2009). Discourse conditions on subject pronoun realization: Testing the linguistic intuitions of bilingual children. Lingua, 119, 460-477. 
Souza, B. J. (2010). Hiatus resolution in Spanish: An experimental study (Unpublished doctoral dissertation). The Pennsylvania State University, University Park, PA.

Zárate-Sández, G. (2011). Speakers' intuitions about L2 syllable structure: Diphthong vs. hiatus resolution in Spanish by English-speaking learners. In L. Plonsky \& M. Schierloh (Eds.), Selected Proceedings of the 2009 Second Language Research Forum (pp. 164-181). Somerville, MA: Cascadilla Proceedings Project. 


\section{NoTES}

1. The underlying representation of glides is a highly contentious topic in theoretical Hispanic linguistics. Here we choose to represent nonsyllabic vocalic segments as glides, [j, w], for expository convenience, with no intended claims regarding their representation. For a recent thorough review of the representation of glides in Spanish, we refer the reader to Roca (2016).

2. As is the case with Spanish, English diphthongs exhibit wide variation across dialects and registers. In this paper, "English" refers to Standard American English, with the understanding that this label implies a necessary level of abstraction from the diverse possible phonetic forms. We have also chosen to present the English diphthongs here with the vowels [a, e, o] and the glides [j, w]. We are aware of alternative transcriptions such as [aI, eI, oI, av, ov, Iu]. This choice was made for ease of comparison between the two languages.

3. This average excludes [ew], which, while a falling diphthong, does not appear in English.

4. As pointed out by an anonymous reviewer, the use of a Spanish population as a comparison to heritage speakers of American varieties of Spanish may appear problematic. It is true that intuitions regarding diphthongization/hiatus have been shown to vary by dialect. For example, some northern-central regions of Spain have been cited to evidence intuitions of exceptional cases of hiatus in vocalic sequences that other speakers consider diphthongs (Hualde, 1999; Hualde \& Prieto, 2002; Simonet, 2005; Cabré \& Prieto, 2006). However, to our knowledge this has not been documented in Andalusia, where our participants live. More importantly, as will be illustrated in the Results and Discussion section, statistical analyses of the monolingual data in this study reveal no significant differences in any critical comparison. This suggests that the Spaniards treat all diphthong types equally and therefore form an appropriate monolingual comparison group.

5. While one participant reports having begun Spanish at the arguably late age of $10, \mathrm{~s} / \mathrm{he}$ also reports having been exposed to the language since birth. An isolated analysis of this participant's syllabification reveals the same general patterns of the overall heritage group, and for that reason the participant's data were not excluded from the study.

6. The imbalance in quantity between rising diphthongs and falling diphthongs, and palatal and velar glides, is due to multiple factors. First, these items were principally culled from ZárateSández (2011), whose stimuli set was also imbalanced, in an attempt to replicate his L2 findings with heritage speakers. Second, the low frequency of certain diphthong types in Spanish, such as [ow], led us to include more rising diphthongs than falling diphthongs, in order to maintain more balance in the other critical comparisons (i.e., cognate status and the hiatus status of the English translations). Lastly, because [ju] is the only rising diphthong permitted in English, and it was excluded from Zárate-Sández (2011), we chose to include the additional items ciudad 'city', triunfo 'triumph', diurno 'daytime', and viuda 'widow', two cognates and two noncognates, respectively, which also added to the increased quantity of rising diphthongs with palatal glides in the present experiment. 